Universidad de Lima

Facultad de Comunicación

Carrera de Comunicación

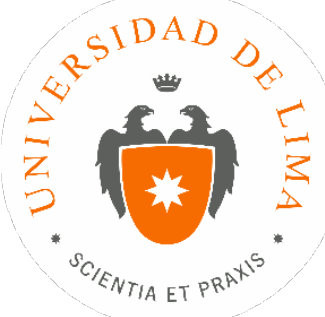

\title{
PLAN DE COMUNICACIÓN ESTRATÉGICO PARA EL LANZAMIENTO Y POSICIONAMIENTO DE LA MARCA AWANA
}

Trabajo de Suficiencia Profesional para optar el Título Profesional de Licenciado en Comunicación

Gonzales Mauricio, Angela Valeria

Código 20070468

Lima - Perú

Setiembre de 2018 


\section{PLAN DE COMUNICACIÓN ESTRATÉGICO PARA EL LANZAMIENTO Y POSICIONAMIENTO DE LA MARCA AWANA}




\section{ÍNDICE}

RESUMEN ...................................................... pág. 5

INTRODUCCIÓN .................................................... pág. 6

I. ANTECEDENTES ............................................... pág. 8

1. Organización

1.1. Confecciones SAC

1.2 Misión y Visión

1.3 Valores corporativos

1.4 Servicios

II. ENTORNO

.pág.10

1. Análisis de la situación externa

2. Análisis dela situación interna

3. FODA

III. DIAGNÓSTICO DE LA COMUNICACIÓN INTERNA

pág. 16

1. Análisis del contexto actual

1.1 Comunicación interna

1.1.1 Públicos objetivos

1.1.2. Herramientas de comunicación interna

1.2 Cultura y Clima Organizacional

1.2.3 Valores

2. Deficiencias detectadas en la comunicación interna

3. Propuesta de mejora

IV. PLAN ESTRATEGICO DE COMUNICACIÓN INTERNA

1. Objetivo y estrategia

2. Propuesta de planeamiento.

3. Propuesta de medios y herramientas

3.1 Acciones tácticas

4. Identidad Corporativa

4.1 Manual de Identidad Corporativa.

5. Campaña interna de lanzamiento.

6. Presupuesto.

7. Indicadores de seguimiento y control, 
1. Diagnóstico

2. Plan de comunicaciones externa

2.2 Objetivo y estrategia.

2.2.1 Objetivo general

2.2.2. Objetivos específicos

2.3 Público objetivo

2.4 Stakeholders

2.5 Mensajes clave

2.6 Estructura del área.

3. Planeamiento estratégico

4. Propuesta de medios y herramientas

4.1 Acciones tácticas

4.2 Cronograma

5. Presupuesto

6. Indicadores de medición e instrumentos de evaluación

VI CONCLUSIONES .................................................pág.51

REFERENCIAS ........................................................pág. 52

ANEXOS ...............................................................pág. 54 


\section{RESUMEN}

El presente trabajo aborda el diagnóstico e implementación de un plan estratégico de comunicaciones de una empresa textil que busca incursionar con un nueva marca y desea posicionarse entre su público interno (colaboradores) y su público externo (clientes, proveedores, medios de comunicación, entre otros).

Es importante ver la comunicación corporativa, como uno de los principales aliados estratégicos de las empresas, y no simplemente como un área de soporte, ya que de una buena gestión y de un buen análisis podemos lograr la realización de los objetivos de la Alta Dirección. 


\section{INTRODUCCIÓN}

Confecciones SAC es una empresa textil que está enfrentándose a retos propios de su sector: la futura migración de sus proveedores por mano de obra barata, las crisis en los mercados extranjeros, el mal clima laboral hacia adentro, la falta de valoración y conocimiento hacia su principal material prima; el algodón pima, el impacto ambiental que puede verse afectado por esta industria y la innovación en sus procesos.

Ante este panorama, la dirección se plantea una re ingeniería en sus procesos y nuevas estrategias: 1) Lanzar una nueva marca que a la vez sea el nombre de la empresa y 2) Investigar nuevos campos de procesos para la elaboración de sus productos.

Al tratarse de una nueva marca, es responsabilidad del equipo de comunicaciones y del Dircom a cargo enfrentarse ante dos escenarios, el interno y el externo, cada uno con sus objetivos y problemáticas.

Como encargada del área de comunicaciones, primero considero importante ahondar en el contexto actual del sector, para después aterrizar y hacer un diagnóstico de ambos escenarios. La importancia de la comunicación estratégica radica en la planeación que se hace previamente para poder acertar con los objetivos y no lanzar acciones sin razón. El reto de Confecciones SAC es crear una nueva marca, y consolidarla en el tiempo.

La propuesta de comunicación aborda herramientas aprendidas en mi campo profesional, así como las aprendidas en clase. 


\section{Antecedentes}

\section{Organización}

\subsection{Confecciones SAC}

Confecciones SAC es una mediana empresa peruana fundada por 3 socios oriundos de Lima. Esta empresa opera en tres distintas localidades: Lima (oficinas administrativas, producción y exportación) Arequipa y Ayacucho (principales proveedores). La empresa cuenta con más de 20 años en el mercado.

\subsection{Misión y Visión}

\subsubsection{Misión:}

Producir prendas de vestir con la más alta calidad en el mercado peruano, respondiendo a las tendencias y gustos de nuestros consumidores, contribuyendo al desarrollo económico del país. Trabajamos para satisfacer los más altas exigencias de nuestros clientes contando con la mejor materia prima de algodón pima orgánico y el equipo humano más especializado del sector. Nuestras operaciones están dirigidas a promover un impacto social y un cuidado del medio ambiente.

\subsubsection{Visión:}

Convertirse en los próximos 10 años en una de las empresas textiles de mayor éxito en el Perú

\subsection{Valores Corporativos}


- Peruanidad

- Calidad

- Compromiso con el medio ambiente

- Innovación

- Colaboración

\subsection{Servicios}

La empresa se dedica a ser proveedora de telas de algodón pima y confecciona para marcas internacionales reconocidas.

Actualmente, la Gerencia General ha visto como estrategia, incursionar en un nuevo servicio: tener una marca propia y posicionarla interna y externamente. 


\section{Entorno}

Como punto de partida, es importante conocer el entorno en el cuál nos estamos desarrollando; esto nos dará una visión más acertada de los principales factores que serán nuestras oportunidades o amenazas y nos permitirá identificar con mayor claridad nuestros objetivos comunicacionales.

\section{Análisis de la situación externa}

a. Factores económicos:

Según la Encuesta de Expectativas Empresariales que realiza el Banco Central de Reserva (BCR), la economía peruana ha registrado un incremento del PBI de $2.9 \%$ en julio a 4\% en agosto y teniendo buenas expectativas para el 2019 donde se calcula un crecimiento entre $3.8 \%$ y $4 \%$.

"En agosto, los tres grupos de agentes económicos mantuvieron estables sus proyecciones de crecimiento del PBI. Los analistas económicos prevén una expansión de 4\%; mientras los representantes del sistema financiero y de las empresas no financieras esperan un crecimiento de $3.8 \%$ y 3.5\%, respectivamente", detalla el comunicado del BCR. (Gestión, 2018)

Con respecto al sector textil, esta industria ha tenido un crecimiento en comparación al año 2017, lo que le está permitiendo salir de la crisis en la que se encontraba. A inicios del año 2018, el ex ministro de producción Pedro Olaechea, proyectó que el año cerraría con una recuperación del 4\% respecto al 2017, lo que representa un futuro favorable 
para sector de prendas de vestir. (Diario Gestión, 2018)

“Esto, junto a la recuperación económica de sus principales compradores del sector externo, podrían ser signos de una recuperación para años posteriores”, acotó.

En cuanto a la economía mundial, la Sociedad Nacional de Industrias (SNI) indicó que la guerra comercial entre Estados Unidos y China, podría representar una ventaja para que a partir de setiembre del año 2018 se realicen más exportaciones a Estados Unidos, con un arancel de entrada en $0 \%$ al mercado americano.

"Con las medidas adecuadas, sectores no tradicionales como la pesca de Consumo Humano Directo pueden generar exportaciones adicionales de US\$ 200 millones anuales. Los envíos de medicinas pueden generar US\$100 millones adicionales; y el sector textil-confecciones podría incrementar sus exportaciones en US\$600 millones”, expresó Márquez. (La República, 2018)

b. Factores tecnológicos:

Hoy en día, uno de los principales retos a los que las empresas PyME peruanas se deben enfrentar es a la incorporación de innovación tecnológica, ya que al encontrarnos en un mercado global, los mercados extranjeros no solo demandan una calidad óptima, sino también menores de tiempos de entrega. (Gestión, 2018)

c. Factores ambientales: 
Durante el año 2017, Perú se vio perjudicado por un fuerte fenómeno del niño que perjudico muchos de los campos de cultivo al norte del país. Hoy en día, la tecnología está encaminada a buscar que este tipo de factores tenga un impacto reducido.

d. Factores legales y tributarios.

Hoy en día, muchos productores textiles que exportan, tienen que enfrentarse a una serie de tributos y regímenes aduaneros para poder sacar sus productos al extranjero. El gobierno, apoya al exportador y ha lanzado el programa "Exporta fácil" que te permite tener trámites aduaneros simplificados, orientación y ayuda al respecto, seguimiento en línea de los productos, créditos y descuentos en los gastos de transporte, entre otros beneficios. (textil, 2015)

\section{Análisis de la situación interna}

- La empresa cuenta con visión y plan estratégico.

- Hay un crecimiento sostenido desde su fundación.

- La cadena de suministro y los colaboradores tienen una alta consideración de la empresa y de sus directivos.

- Son considerados como socios clave por sus Partners comerciales en el extranjero.

- Alta competitividad con mercados chinos.

- Principal valor agregado es la calidad de su materia prima.

- Alta rotación entre sus colaboradores y porcentaje bajo en engagement. 
- No existe hasta el momento un área de comunicaciones que se encargue de liderar las comunicaciones.

- Existe una cultura corporativa débil.

- Existe una necesidad de innovar los procesos productivos.

- La empresa tiene preocupación por el impacto ambiental.

\section{FODA}
A. Fortalezas

- Trayectoria con más de 20 años como proveedora de telas de algodón lima y confecciones para marcas internacionales reconocidas.

- Operaciones en 3 localidades distintas: Lima (sede principal), Arequipa y Ayacucho (principales proveedores).

- Fuertes lazos con sus proveedores y socios en provincias.

- La cadena de suministro y los colaboradores tienen una alta consideración de la empresa y de sus directivos.

- Son considerados como socios clave por sus Partners comerciales en el extranjero.

B. Debilidades

- El 80\% de colaboradores considera su trabajo rutinario.

- El índice de rotación es relativamente alto. 
- Solo el 30\% recomendaría a otros trabajar ahí.

- Apenas el $20 \%$ consideran que son escuchados.

- Cultura corporativa débil.

- Hasta la fecha no había un área de comunicaciones.

- No hay innovación en los canales de comunicación.

C. Oportunidades

- Alta percepción del mercado peruano como principal exportador de algodón pima.

- Excelentes condiciones climáticas apropiadas para el cultivo de algodón pima.

- El algodón pima es reconocido como patrimonio genético y étnico cultural del Perú.

- Tratados de libre comercio con varios países.

- Conformación de distintos gremios y sociedades que brindan soporte a los emprendedores y empresarios del sector, tal como el Instituto peruano del Algodón (IPE), la Sociedad Nacional de Industrias (SNI), Asociación de Exportadores (ADEX), entre otros.

D. Amenazas

- Aún no hay un apoyo total del gobierno hacia las pequeñas y medianas empresas; a pesar de que en los 
últimos años se han desarrollado acciones para incentivar más este sector.

- Mano de obra barata en países asiáticos.

- Fuerzas climatológicas como el Fenómeno del niño destruyen los campos de cultivo y elevan el precio de la materia prima. 


\section{Diagnóstico de la Comunicación Interna}

Para poder crear una nueva gestión en la comunicación es necesario abordar un breve análisis del contexto actual de comunicación interna en Confecciones SAC. Este análisis también abarca factores que involucran la cultura y el clima organizacional de la compañía.

\section{Análisis del Contexto Actual}

\subsection{Comunicación interna:}

Durante estos años, no ha existido un departamento de comunicaciones, ni un encargado de comunicación interna.

La comunicación hacia los colaboradores la ha desempeñado la jefa de recursos humanos ocasionalmente, con ayuda de colaboradores voluntarios.

Sus objetivos han girado en torno a la organización de eventos durante el año.

De acuerdo al nuevo equipo administrativo, se espera que el área de comunicaciones se concrete y establezca líneas estratégicas para mantener una buena cultura entre sus colaboradores.

\subsubsection{Públicos objetivos}

- Personal administrativo: involucra a todo el personal que realiza trabajo de oficina, y de soporte administrativo. Ellos cuentan con una computadora a su cargo.

- Personal de operaciones (fabricación y exportación): involucra a todo el personal que trabaja en la producción y fabricación de los productos. No cuentan con computadora a su cargo (necesariamente) y usualmente se encuentran en planta. 


\subsubsection{Herramientas de comunicación interna}

En la actualidad, no hay una estructura sostenida de comunicaciones; sin embargo, se han dado iniciativas que son consideradas medios y canales de comunicación.

\begin{tabular}{|c|c|c|c|}
\hline Tipo & Público atendido & Medios/Canales & Frecuencia \\
\hline Físico & Personal completo & Murales & Permanente \\
\hline Físico & $\begin{array}{l}\text { Personal } \\
\text { administrativo }\end{array}$ & Boletín interno & 1 vez al año \\
\hline Electrónico & Personal completo & Página web & Permanente \\
\hline Electrónico & $\begin{array}{l}\text { Personal } \\
\text { administrativo }\end{array}$ & Correo electrónico & Permanente \\
\hline Electrónico & $\begin{array}{l}\text { Personal } \\
\text { administrativo }\end{array}$ & $\begin{array}{l}\text { Grupo de } \\
\text { Facebook }\end{array}$ & $\begin{array}{l}\text { Ocasionalmente } \\
\text { (Poco uso) }\end{array}$ \\
\hline
\end{tabular}

\subsection{Cultura y Clima Organizacional}

Un área de comunicación interna tiene como objetivo además, dar soporte al área de recursos humanos, para una correcta medición de la cultura y clima organizacional. En Confecciones SAC, se realizaron encuestas de cultura y clima laboral que arrojaron lo siguiente:

- Índice de rotación alto: el $80 \%$ de los colaboradores considera su trabajo rutinario.

- El $70 \%$ son mujeres, con una edad promedio de 30 años.

- Sentido de pertenencia bajo: solo el 30\% recomendaría su trabajo.

- No hay sentimiento de pertenencia, porque no se sienten escuchados. Solo el 20\% considera sentirse escuchados. 
- Valores detectados de la cultura: pulcritud, dedicación, disciplina, puntualidad.

El caso solo precisa que además de los canales de comunicación previamente presentados, la organización realiza pequeños eventos puntuales a lo largo del año, más no se tiene mayor información de estos.

\subsubsection{Valores}

- Pulcritud: al ser una planta textil, y en su mayoría un área de operaciones, todos los procesos, insumos, procedimientos deben llevarse en un clima de orden. Sin orden, podrían retrasar los pedidos o perder información valiosa.

- Dedicación: es lo que caracteriza a los colaboradores de Confecciones SAC.

- Disciplina: en conjunto con el orden y la pulcritud, la disciplina es un factor que distingue la cultura de Confecciones SAC.

- Puntualidad: para un área de producción, lo más importante es estar al día con los tiempos en el canal de procesos, desde el proveedor hasta el cliente. 


\section{Deficiencias detectadas en comunicación interna}

Acciones

Ausencia de equipo y responsable de comunicaciones

Desconocimiento y ausencia de plan estratégico

Pocos canales de comunicación

No hay una real valoración de la comunicación

No hay claridad en los procedimientos

Cultura corporativa débil

No hay cultura de retroalimentación o Feedback

\section{Detalle}

Hasta el momento, no se consideraba importante la existencia de un departamento de comunicaciones, y estas acciones son realizadas por personal poco capacitado o con poca experiencia en el tema.

Todo mensaje debería estar orientado a fortalecer los lineamientos estratégicos, y dar a conocer los objetivos organizacionales, sin embargo, no es el caso de Confecciones SAC

Se ha detectado una insuficiente cantidad de canales de comunicación que no responde a las necesidades de los colaboradores y deja sin atender al público más grande de la organización.

Se encuentran buenas iniciativas; no obstante, no tienen la frecuencia o dedicación esperadas.

No hay procedimientos de comunicación detectados, desde el onboarding del colaborador hasta el final del convenio laboral.

Como consecuencia de la falta de comunicación, la cultura organizacional de Confecciones SAC se muestra baja, desembocando con otros indicadores de gestión humana que pueden afectar en el sentido de pertenencia, rotación de colaboradores en un sector tan especializado, ocasionando pérdidas futuras innecesarias.

Los colaboradores no se sienten escuchados por sus supervisores o por sus jefes directos.

\section{Propuestas de mejora}


La Dirección ejecutiva de Confecciones SAC ha aprobado la creación de un departamento y equipo de Comunicaciones, que, en conjunto con el área de recursos humanos, crearan estrategias, políticas y lineamientos que soporten los objetivos organizacionales de la empresa. 


\section{Plan estratégico de Comunicación Interna}

"La comunicación ha sido a menudo tomada como una moda. Ahora se va convirtiendo en una cultura. La fuerza de las cosas empieza por dejar bien claro que las organizaciones son centros emisores y receptores de señales, informaciones, mensajes, comunicación; que ésta se diversifica y se densifica constantemente; que sus técnicas se especializan y proliferan; que el tráfico comunicacional aumenta al volumen y tiende a la saturación y al desorden. (...)

La necesidad crea el órgano. Surge así el imperativo de un nuevo especialista: el generalista polivalente, que sea al mismo tiempo estratega, comunicador (portavoz), gestor de las comunicaciones, y además guardián de la imagen corporativa." (autores, 2000)

Tal como lo citado, "la necesidad crea el órgano" y ante esta necesidad se presentan las propuestas de comunicación interna para Confecciones SAC, como respuesta al diagnóstico previamente analizado.

Para la consultora chilena INSIDECOM, un modelo de comunicación interna estratégica se puede expresar mediante el siguiente modelo 
Plan estratégico de comunicación interna
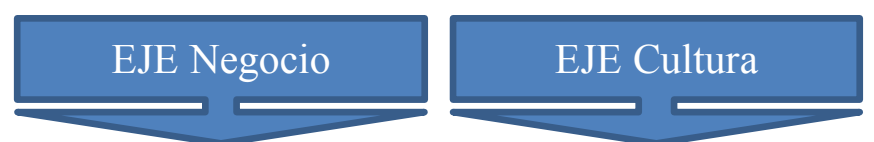

\section{EJE Personas}
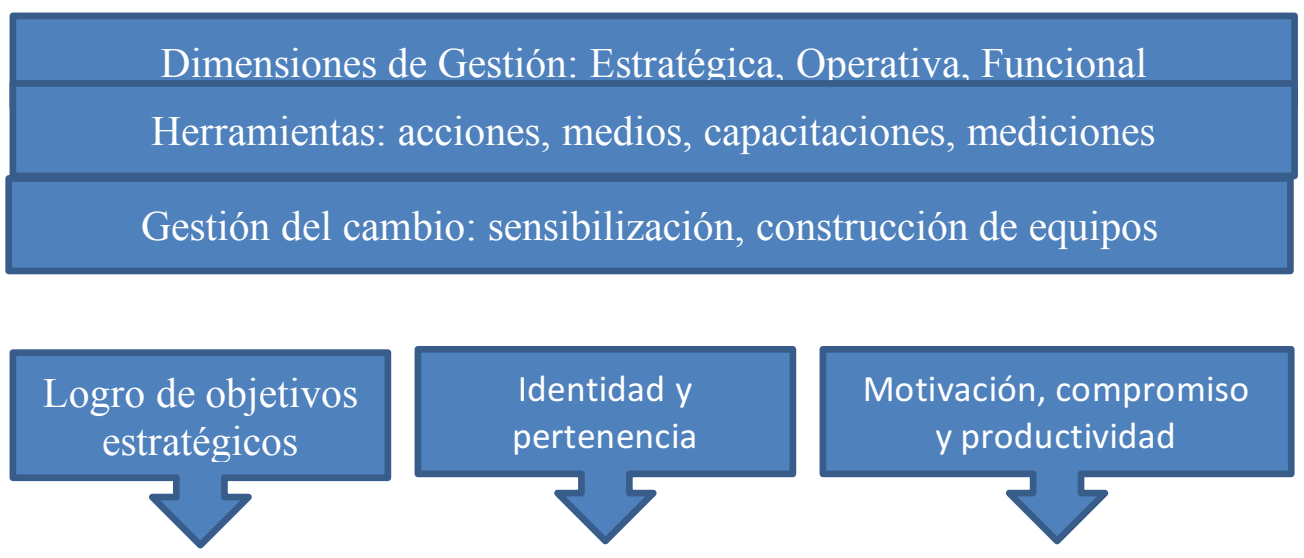

Motivación, compromiso y productividad

\section{Evaluación de la gestión}

\section{Objetivo y Estrategia}

Crear una cultura comunicacional en la organización que contribuya a la identidad corporativa, y que, de soporte a los objetivos organizacionales, consolidando una cultura corporativa.

\subsection{Ejes fundamentales y objetivos}

\section{i) Eje Negocio}

(1) Dar a conocer los objetivos del negocio y el plan estratégico de la empresa. 
(2) Comunicar correctamente los cambios organizacionales.

(3) Incentivar y fomentar el diálogo entre los colaboradores y la empresa.

\section{ii) Eje Cultura}

(1) Desarrollar e implementar la nueva identidad corporativa de la marca.

(2) Dar a conocer los valores corporativos.

(3) Promover las iniciativas y las buenas ideas innovadoras.

(4) Conseguir que toda la organización se comprometa con la marca.

\section{iii) Eje Personas}

(1) Cohesionar la identidad y mejorar el sentido de pertenencia.

(2) Dar soporte para la mejora del clima laboral.

(3) Mantener motivados y comprometidos a los colaboradores.

\subsection{Público Objetivo}

Debido al cambio organizacional de la firma, propongo una segmentación diferente a la ya establecida:

- Personal ejecutivo: esta segmentación incluye a los accionistas, ejecutivos y niveles gerenciales de la organización. Sus decisiones influyen directamente en las acciones de la compañía.

- Personal de soporte administrativo.

- Personal de fábrica y operativo.

\subsection{Estructura del área}


Analista de comunicaciones internas
Analista de

comunicaciones

externas y RR.PP
Diseñador

Gráfico

- Director de comunicaciones (DIRCOM): será el responsable del área de comunicaciones y el intermediario entre la gerencia general y su equipo. Es responsabilidad del dircom, desarrollar el Plan de Comunicación Interna, cuya finalidad es la de fomentar el sentimiento de pertenencia de los colaboradores, generando una cultura organizacional que beneficio a todos y que se exprese en la identidad corporativa, generando flujos viables de comunicación entre todas las áreas.

Como resultado de este plan, tiene como meta fidelizar al público interno a nuestra marca, y un entorno que motiva a los colaboradores a sentirse parte del desarrollo del Perú.

El dircom debe trabajar de la mano con la gerencia general y el área de recursos humanos.

- Jefe de Comunicaciones y RR. PP: será el responsable de la gestión y cuidado de la imagen de la institución, mediante la ejecución de planes 
de comunicación interna y externa, estableciendo networking con otros profesionales del medio, medios de comunicación y grupos de interés.

- Analista de comunicaciones internas: será el encargado de la implementación del plan de comunicación interna y de los procesos que involucren a esta. Así mismo, su responsabilidad será dar soporte a recursos humanos en las necesidades que tenga.

- Analista de comunicaciones externas: será el encargado en dar soporte a la gestión de la comunicación externa, relacionándose con medios de comunicación, grupos de interés, además de brindar soporte de comunicación del área de desarrollo sostenible. Además, debe trabajar de la mano con el área de marketing el lanzamiento de la nueva marca de la compañía, supervisando los estándares de comunicación en medios publicitarios.

- Diseñador gráfico: será el responsable de la gráfica de la compañía, preocupándose de respetar el manual de estilo, y reforzando la identidad en las distintas comunicaciones que se requieran.

- Practicante profesional de comunicaciones: Asistir a comunicación interna y comunicación externa en cualquier requerimiento que se requiera. Este personal está en etapa formativa.

\section{Propuesta de planeamiento}




\subsection{EJE Negocio}

\begin{tabular}{|c|c|c|c|c|c|c|}
\hline Objetivo & Estrategia & Acciones/medios & Tipo & Público & Frecuencia & Responsable \\
\hline $\begin{array}{r}\text { Dar a conocer los } \\
\text { objetivos del } \\
\text { negocio y el plan } \\
\text { estratégico de la } \\
\text { empresa. }\end{array}$ & $\begin{array}{l}\text { Generar espacios } \\
\text { donde se } \\
\text { comunique } \\
\text { abiertamente los } \\
\text { objetivos y visión } \\
\text { de la empresa para } \\
\text { los próximos años. }\end{array}$ & $\begin{array}{l}\text { 1. Desayuno informativo } \\
\text { del CEO con todos las } \\
\text { gerencias de áreas. } \\
\text { 2. Desayunos de diálogo } \\
\text { con áreas y sus gerentes de } \\
\text { área. }\end{array}$ & presencial & $\begin{array}{l}\text { 1. Ejecutivo } \\
\text { 2. Administrativos } \\
\text { y Planta. }\end{array}$ & $\begin{array}{l}\text { 1. Ocasionalmente } \\
\text { 2. Semestralmente }\end{array}$ & $\begin{array}{l}\text { Director de } \\
\text { Comunicaciones }\end{array}$ \\
\hline $\begin{array}{r}\text { Comunicar } \\
\text { correctamente los } \\
\text { cambios } \\
\text { organizacionales. }\end{array}$ & $\begin{array}{l}\text { Generar espacios y } \\
\text { medios para } \\
\text { comunicar los } \\
\text { cambios } \\
\text { organizacionales } \\
\text { de la compañía } \\
\text { (producto de la } \\
\text { estrategia), nuevas } \\
\text { áreas y } \\
\text { presentación de } \\
\text { nuevos ejecutivos. }\end{array}$ & $\begin{array}{l}\text { 1. Comunicado correo } \\
\text { electrónico del GG. } \\
\text { Mensaje: "Para crecer, hay } \\
\text { que cambiar" } \\
\text { 2. Anuncio en Murales } \\
\text { 3. Reunión informativa del } \\
\text { CEO con todas las áreas. }\end{array}$ & $\begin{array}{l}\text { 1. Electrónico } \\
\text { 2. Físico } \\
\text { 3. Presencial }\end{array}$ & $\begin{array}{l}\text { 1. Administrativos } \\
\text { 2. Administrativos } \\
\text { y Planta. } \\
\text { 3. Administrativos } \\
\text { y Planta. }\end{array}$ & Una vez. & $\begin{array}{l}\text { Comunicaciones } \\
\text { internas }\end{array}$ \\
\hline $\begin{array}{r}\text { Incentivary } \\
\text { fomentar el diálogo } \\
\text { entre los } \\
\text { colaboradores y la } \\
\text { empresa }\end{array}$ & $\begin{array}{l}\text { Crear espacios y } \\
\text { canales de diálogo } \\
\text { entre los } \\
\text { colaboradores y } \\
\text { los ejecutivos que } \\
\text { permita tener una } \\
\text { comunicación } \\
\text { puertas abiertas. }\end{array}$ & $\begin{array}{l}\text { 1. Crear espacio "Café en } \\
\text { la oficina" donde se invite } \\
\text { a los colaboradores a } \\
\text { poder conversar con los } \\
\text { líderes de la organización } \\
\text { mientras comparten un } \\
\text { aperitivo. } \\
\text { 2. Implementación del } \\
\text { Buzón de Sugerencias "Te } \\
\text { escuchamos" } \\
\text { 3. Creación del correo } \\
\text { electrónico de } \\
\text { comunicaciones. }\end{array}$ & $\begin{array}{l}\text { 1. Presencial } \\
\text { 2. Físico } \\
\text { 3. Electrónico }\end{array}$ & Todo el personal & $\begin{array}{l}\text { 1. Trimestral } \\
\text { 2. Permanente } \\
\text { 3. Permanente }\end{array}$ & $\begin{array}{l}\text { Comunicaciones } \\
\text { internas }\end{array}$ \\
\hline
\end{tabular}

\begin{tabular}{|c|c|c|c|c|c|c|c|c|c|c|c|c|}
\hline \multicolumn{11}{|c|}{ Año 2019} & \multirow[b]{2}{*}{ Nov } & \multirow[b]{2}{*}{$\mathrm{Dic}$} \\
\hline Objetivos & Ene & Feb & Mar & Abr & May & Jun & Jul & Ago & Set & Oct & & \\
\hline $\begin{array}{l}\text { Dar a conocer los objetivos del negocio y el } \\
\text { nuevo plan estratégico de la empresa }\end{array}$ & $x$ & & & & & & & & & & & \\
\hline $\begin{array}{l}\text { Comunicar correctamente los cambios } \\
\text { organizacionales }\end{array}$ & $x$ & $x$ & $\mathrm{x}$ & & & & & & & & & \\
\hline $\begin{array}{l}\text { Incentivar y fomentar el diálogo entre los } \\
\text { colaboradores y la empresa }\end{array}$ & $x$ & $x$ & $x$ & $x$ & $x$ & $x$ & $x$ & $x$ & $x$ & $x$ & $x$ & $x$ \\
\hline
\end{tabular}

\subsection{EJE Cultura}




\section{Objetivo}

\begin{tabular}{|c|c|c|c|c|c|c|}
\hline $\begin{array}{r}\text { Desarrollar e } \\
\text { implementar la } \\
\text { nueva identidad } \\
\text { corporativa de la } \\
\text { marca. }\end{array}$ & $\begin{array}{l}\text { 1. Crear la } \\
\text { identidad } \\
\text { corporativa. } \\
\text { 2. Idear campaña } \\
\text { de lanzamiento de } \\
\text { marca interna. } \\
\text { 3. Medir la } \\
\text { afiliación a la } \\
\text { marca. }\end{array}$ & $\begin{array}{l}\text { 1. Desarrollar manual de } \\
\text { estilo, y alinear todas las } \\
\text { comunicaciones a este. } \\
\text { 2. Campaña } 360 \text { de } \\
\text { lanzamiento de nueva } \\
\text { marca. } \\
\text { 3. Medir con ayuda de } \\
\text { instrumentos de medición }\end{array}$ & & Todos & Según ocasión & $\begin{array}{l}\text { Director de } \\
\text { Comunicaciones y } \\
\text { equipo. }\end{array}$ \\
\hline $\begin{array}{c}\text { Dar a conocer los } \\
\text { valores corporativos }\end{array}$ & $\begin{array}{l}\text { Crear campañas de } \\
\text { valores para } \\
\text { difundirlos en toda } \\
\text { la organización. }\end{array}$ & $\begin{array}{l}\text { 1. Activación en planta y } \\
\text { oficina. } \\
\text { 2. Señalética en sala de } \\
\text { reuniones y salas comunes. } \\
\text { "Awana es peruanidad" } \\
\text { 3. Boletín físico } \\
\text { 4. Difusión constante en } \\
\text { discursos de líderes. } \\
\text { 5. Realización de eventos } \\
\text { afines a los valores. }\end{array}$ & Todos. & Todos & Constantemente & $\begin{array}{l}\text { Comunicaciones } \\
\text { internas }\end{array}$ \\
\hline $\begin{array}{r}\text { Promover las } \\
\text { iniciativas y las } \\
\text { buenas ideas } \\
\text { innovadoras. }\end{array}$ & $\begin{array}{l}\text { Crear concursos } \\
\text { donde los } \\
\text { colaboradores } \\
\text { puedan presentar } \\
\text { proyectos } \\
\text { desarrollados por } \\
\text { ellos mismos }\end{array}$ & $\begin{array}{l}\text { 1. Creación del concurso } \\
\text { interno "Peruanos de } \\
\text { innovación" que invita a } \\
\text { todos los colaboradores a } \\
\text { crear proyectos de } \\
\text { innovación en sus } \\
\text { respectivas áreas o para } \\
\text { algún beneficio de la } \\
\text { compañía. } \\
\text { 2. Comunicación en correo } \\
\text { electrónico y murales. }\end{array}$ & $\begin{array}{l}\text { 1. Presencial } \\
\text { 2. Físico } \\
\text { 3. Electrónico }\end{array}$ & Todos & $\begin{array}{l}\text { 1. Trimestral } \\
\text { 2. Permanente } \\
\text { 3. Permanente }\end{array}$ & $\begin{array}{l}\text { Comunicaciones } \\
\text { internas }\end{array}$ \\
\hline
\end{tabular}

Tiempo: trimestres (2019-2021)

\begin{tabular}{|c|c|c|c|c|c|c|c|c|c|c|c|c|}
\hline Objetivos & 1 & 2 & 3 & 4 & 5 & 6 & 7 & 8 & 9 & 10 & 11 & 12 \\
\hline $\begin{array}{l}\text { Desarrollar e implementar la } \\
\text { nueva identidad corporativa de } \\
\text { la marca. }\end{array}$ & $\mathrm{x}$ & & & & $\mathrm{X}$ & & & & $\mathrm{X}$ & & & \\
\hline $\begin{array}{l}\text { Dar a conocer los valores } \\
\text { corporativos }\end{array}$ & $\mathrm{X}$ & $\mathrm{X}$ & $\mathrm{X}$ & $\mathrm{X}$ & $\mathrm{X}$ & $\mathrm{X}$ & $\mathrm{X}$ & $\mathrm{X}$ & $\mathrm{X}$ & $\mathrm{X}$ & $\mathrm{X}$ & $\mathrm{X}$ \\
\hline $\begin{array}{l}\text { Promover las iniciativas } \\
\text { y las buenas ideas } \\
\text { innovadoras. }\end{array}$ & & & $\mathrm{X}$ & & & & $\mathrm{X}$ & & & & $\mathrm{X}$ & \\
\hline $\begin{array}{l}\text { Conseguir que toda la } \\
\text { organización se comprometa } \\
\text { con la marca. }\end{array}$ & $\mathrm{X}$ & $\mathrm{X}$ & $\mathrm{X}$ & $\mathrm{X}$ & $\mathrm{X}$ & $\mathrm{X}$ & $\mathrm{X}$ & $\mathrm{X}$ & & & & \\
\hline
\end{tabular}




\subsection{EJE Personas}

\begin{tabular}{|c|c|c|c|c|c|c|}
\hline Objetivo & Estrategia & Acciones/medios & Tipo & Público & Frecuencia & Responsable \\
\hline $\begin{array}{l}\text { Cohesionar la } \\
\text { identidad y mejorar } \\
\text { el sentido de } \\
\text { pertenencia. }\end{array}$ & \begin{tabular}{l}
\multicolumn{1}{c}{ 1. Crear } \\
programas \\
conforme a los \\
públicos objetivos \\
de la empresa.
\end{tabular} & $\begin{array}{l}\text { 1. Insertar a las mujeres en } \\
\text { programas de desarrollo y } \\
\text { empoderamiento } \\
\text { femenino. (Son el mayor } \\
\text { porcentaje de los } \\
\text { colaboradores) } \\
\text { \#MujeresDelPerú }\end{array}$ & Todos & Todos & Según ocasión & $\begin{array}{l}\text { Comunicaciones } \\
\text { internas }\end{array}$ \\
\hline $\begin{array}{l}\text { Dar soporte } \\
\text { para la mejora del } \\
\text { clima laboral }\end{array}$ & $\begin{array}{l}\quad \text { 1. Presentar } \\
\text { acciones que } \\
\text { atiendan los } \\
\text { puntos más bajos } \\
\text { de la encuesta de } \\
\text { clima. } \\
\quad \text { 2. Realizar } \\
\text { eventos y talleres } \\
\text { con ocasiones } \\
\text { especiales. }\end{array}$ & Definir con RRHH & Todos. & Todos & Constantemente & $\begin{array}{l}\text { Comunicaciones } \\
\text { internas }\end{array}$ \\
\hline \begin{tabular}{l}
\multicolumn{1}{c}{ Mantener } \\
motivados y \\
comprometidos a los \\
colaboradores.
\end{tabular} & $\begin{array}{l}\text { 1. Implementar un } \\
\text { plan de beneficios } \\
\text { corporativos. } \\
\text { 2. Plantear un } \\
\text { programa de } \\
\text { reconocimiento }\end{array}$ & Definir con RRHH & Todos & Todos & Constatemente & $\begin{array}{l}\text { Comunicaciones } \\
\text { internas }\end{array}$ \\
\hline
\end{tabular}

Tiempo: trimestres (2019-2021)

\begin{tabular}{|c|c|c|c|c|c|c|c|c|c|c|c|c|}
\hline Objetivos & 1 & 2 & 3 & 4 & 5 & 6 & 7 & 8 & 9 & 10 & 11 & 12 \\
\hline $\begin{array}{l}\quad \text { Desarrollar e } \\
\text { implementar la nueva } \\
\text { identidad corporativa de la } \\
\text { marca. }\end{array}$ & & & $x$ & $x$ & $x$ & $x$ & & & & & & \\
\hline $\begin{array}{l}\text { Dar soporte para la mejora } \\
\text { del clima laboral }\end{array}$ & $x$ & $x$ & $x$ & $x$ & $x$ & $x$ & $x$ & $x$ & $x$ & $x$ & $x$ & $x$ \\
\hline $\begin{array}{l}\text { Mantener motivador y } \\
\text { comprometidos a los } \\
\text { colaboradores }\end{array}$ & & $x$ & & $x$ & & $x$ & & $x$ & & $x$ & & $x$ \\
\hline
\end{tabular}




\section{Propuesta de medios y herramientas}

\begin{tabular}{|c|c|c|c|}
\hline Tipo & Público atendido & Medios/Canales & Frecuencia \\
\hline Físico & Personal completo & $\begin{array}{l}\text { Pantallas LED } \\
\text { Informativas }\end{array}$ & Permanente \\
\hline Físico & $\begin{array}{l}\text { Personal } \\
\text { administrativo }\end{array}$ & $\begin{array}{l}\text { Boletín interno } \\
\text { "Comunicándonos } \\
\text { con Awana" }\end{array}$ & Bimestral \\
\hline Electrónico & Todos & Página web & Permanente \\
\hline Electrónico & $\begin{array}{l}\text { Personal } \\
\text { administrativo }\end{array}$ & Correo electrónico & Permanente \\
\hline Electrónico & $\begin{array}{l}\text { Personal } \\
\text { administrativo }\end{array}$ & Grupo de Facebook & Permanente \\
\hline Físico & Todos & Tablón de anuncios & Permanente \\
\hline Físico & Todos & $\begin{array}{l}\text { Buzón de } \\
\text { Sugerencias "Awana } \\
\text { te escucha" }\end{array}$ & Permanente \\
\hline Electrónico & Todos & $\begin{array}{l}\text { Comunicados } \\
\text { internos vía correo }\end{array}$ & Cuando lo amerite \\
\hline Presencial & Personal de planta & $\begin{array}{l}\text { Reuniones "Al } \\
\text { toque" }\end{array}$ & Semanal \\
\hline Electrónico & $\begin{array}{l}\text { Personal } \\
\text { administrativo }\end{array}$ & Intranet & Permanente \\
\hline Presencial & Todos & $\begin{array}{l}\text { Reuniones "Café en } \\
\text { la oficina" }\end{array}$ & Trimestral \\
\hline Físico + presencial & $\begin{array}{l}\text { Todos (nuevos } \\
\text { ingresos) }\end{array}$ & Kit de onboarding & Cuando lo amerite \\
\hline Físico + electrónico & Todos & $\begin{array}{l}\text { Wallpapers } \\
\text { (administrativo) e } \\
\text { individuales (planta) }\end{array}$ & $\begin{array}{l}\text { Solo en caso de } \\
\text { campañas } \\
\text { importantes. }\end{array}$ \\
\hline
\end{tabular}

\subsection{Acciones tácticas}

Pantallas LED 


\section{Reestructuración boletín interno \\ "Awana para ti"}

Contenido: Awana para ti tendrá una estructura 30 - 40 - 30. Esto será representado en $20 \%$ (información del sector, cultura general de temas que involucran el negocio textil del Perú y del mundo), $40 \%$ temas de interés personales (entrevistas a los mismos colaboradores de temas de intéres: mamás y trabajadoras, sitios para visitar en lima, etc); 30\% comunicación de RRHH, (eventos, reconocimientos, temas internos de la empresa)

Fotografía: La fotografía será profesional, pero que retrate a la familia Awana, colaboradores entre amigos, mirando a la cámara, sonriendo.

Colores: corporativos.

Mensaje clave: familia Awana, somos awana, construimos juntos Awana.

Nueva página web

Correo electrónico interno
Se renovará la página web con nuevos contenidos. (Responsable: comunicación externa + marketing)

- Contenidos de comunicación interna en sección "Comunidad Awana"

\section{Tablón de anuncios}

Este tablón está enfocado más en comunicaciones personales de los colaboradores.

Ejm: si desean vender algo o recomiendan algún emprendimiento propio de ellos.
“Awana te escucha” (buzón de sugerencias)
Instalar 2 buzones de sugerencia (planta y oficinas) donde los colaboradores puedan escribir dudas, consultas y recomendaciones.

- Se busca que el buzón no sea comunicado con el nombre "de sugerencias" sino como un espacio físico que incentive el diálogo y permita que el colaborador se sienta escuchado.

\section{Reuniones "Al toque"}

Reuniones semanales que los jefes de división tendrán con los colaboradores de planta.

- En ella se tocarán diversos temas y tendrá una duración de 15 minutos al inicio de cada semana. 


\title{
4. Identidad corporativa
}

\begin{abstract}
AWANA
Awana viene de la palabra quechua "telar"

El quechua es una familia de idiomas que proviene de la región andina. Hoy en día es patrimonio y tradición oral del Perú, por lo que simbólicamente se escogió para representar una marca llena de peruanidad.

El concepto hacia adentro (comunicación interna) es "Awana lo construyes tú" (que vendría a ser, este telar lo construyes tú) y el concepto externo es "Perú en una prenda" simbolizando a un gran telar lleno de colores, contrastes, diversidad.

Awana es el Perú y en sus prendas está representada la diversidad cultural y ecológica de cada una de las zonas del Perú, jugando con los colores de nuestra flora, fauna, ecosistemas, paisajes en general. Tal como lo dice el slogan, es "Perú en una prenda"
\end{abstract}

\subsection{Manual de Identidad Corporativa}

En este manual se proponen los elementos de la Identidad visual de Awana. Se establecen las pautas de uso del logo, el uso de las tipografías, los colores corporativos y las recomendaciones de uso en distintos contextos. (Ver anexo) 


\section{Campaña interna de lanzamiento}

La campaña de comunicación interna busca consolidar la nueva marca en el público interno antes de lanzarla hacia fuera.

El concepto de la campaña es “Awana lo construyes tu” y se dividirá en fases de comunicación para que aterrice más en la mente de los colaboradores.

\section{- Pre campaña}

Antes de iniciar la campaña, es importante sensibilizar y alinear a todos los colaboradores de la compañía ante todos los cambios y la reingeniería que atravesará la empresa en sus procesos. Es necesario que el equipo de comunicaciones utilice el "cambio" como herramienta de empowerment, ya que usualmente tiene una percepción negativa hacia los empleados.

En un primer momento se generará una reunión (desayuno) entre el gerente general y sus gerentes de área donde les comunicará los cambios organizacionales y objetivos estratégicos que ha tomado la empresa.

Posterior a esto los gerentes y jefes de área tendrán una reunión con sus equipos acerca de los nuevos objetivos que la compañía se ha planteado para este año. Es importante que el mensaje central de la reunión sea "Queremos que seas parte de esta realidad"

Una vez terminadas las reuniones, el Gerente General enviará un correo electrónico (firmado por él) con un tenor bastante cercano y amigable donde explicará los cambios organizacionales, incluyendo la presentación a los nuevos equipos humanos que se suman a la empresa y sus respectivos directores. El mensaje clave de este correo es: "Para crecer, hay que cambiar" 
(A los colaboradores que no cuentan por correo, se les leerá el mail en reuniones con sus jefes directos).

Una vez enviado el correo, se programarán reuniones donde el mismo gerente general hará una presentación a todos los colaboradores presentando los cambios organizacionales y bajo un concepto motivador.

\section{- Fase Intriga (un mes antes del lanzamiento)}

Esta fase, tendrá por objetivo generar expectativa en torno a lo que va a suceder, de ese modo sensibilizamos al colaborador, y lo mantenemos a la espera.

- Acción 1: Día lunes, semana 1, los colaboradores llegan a su sitio y encuentran una semilla de planta de algodón en una bolsita con un mensaje que dice "prepárate para crecer"

- Acción 2: Día martes, semana 2, se deja una bolsita con un pedazo de algodón, esta vez con un mensaje que dice "vas bien, sigue así”

- Acción 3: Día martes, semana 3, se deja un retaso de tela en los sitios de cada colaborador, con un mensaje que dice "solo somos una parte de lo que se viene"

Adicionalmente a estas acciones, se instalan carteles en las oficinas, colgantes en los sitios de trabajo, wallpaper en las pc's y afiches en los murales con la frase "prepárate para crecer"

La última semana previa al lanzamiento se envía un correo y afiches en los murales a todos los colaboradores con el mensaje "El Perú es un gran telar que construimos todos juntos" e invitándolos a un evento interno (jornada) a modo de evento de integración. 


\section{- Fase de lanzamiento}

- Acción 1: Evento de integración con todos los colaboradores. En este evento se hace el lanzamiento oficial de una manera dinámica y se hace bajo un clima de juegos y motivador.

- Acción 2: Durante el evento todos los colaboradores recibirán un polo con una tarjeta que dice "te presentamos Awana."

El diseño del polo en la parte delantera dice "Somos Awana", y en la parte posterior dice "Somos Perú"

- Acción 3: Toda la papelería, gráfica, wallpapers, afiches, se cambia bajo el slogan "Awana lo construyes tú"

○ Acción 4: Envío de correos electrónicos y explicando que es Awana, y lo que vendrá más adelante. En el caso de los colaboradores de planta, tendrán un individual de papel en el comedor. En este correo se lanzará un spot de 50 segundos

\section{- Fase de mantenimiento}

A partir de esta etapa todas las comunicaciones que salgan serán bajo la línea gráfica propuesta en el manual de identidad corporativa.

En conjunto con recursos humanos, se propondrán acciones como capacitaciones y talleres para los colaboradores.

\section{- Fase de medición}

a. Encuesta de comunicaciones.

b. Entrevistas a profundidad.

c. Entrevistas con jefe.

d. Focus group 


\begin{tabular}{|c|c|c|c|c|c|c|c|c|c|c|c|c|c|c|c|c|c|c|c|c|c|c|c|c|}
\hline \multirow{2}{*}{ Actividades } & \multicolumn{4}{|c|}{ Mes 1} & \multicolumn{4}{|c|}{ Mes 2} & \multicolumn{4}{|c|}{ Mes 3} & \multicolumn{4}{|c|}{ Mes 4} & \multicolumn{4}{|c|}{ Mes 5} & \multicolumn{4}{|c|}{ Mes 6} \\
\hline & S1 & $\mathrm{S} 2$ & S3 & $\$ 4$ & S1 & S2 & S3 & S4 & S1 & $\mathrm{S} 2$ & S3 & \$4 & S1 & $\$ 2$ & S3 & $\$ 4$ & S1 & S2 & S3 & S4 & S1 & \$2 & S3 & \$4 \\
\hline Pre-campaña & & & & & & & & & & & & & & & & & & & & & & & & \\
\hline Intriga & & & & & & & & & & & & & & & & & & & & & & & & \\
\hline Lanzamiento & & & & & & & & & & & & & & & & & & & & & & & & \\
\hline Mantenimiento & & & & & & & & & & & & & & & & & & & & & & & & \\
\hline Medición & & & & & & & & & & & & & & & & & & & & & & & & \\
\hline
\end{tabular}

\section{Presupuesto del Plan de Comunicación Interna}

\begin{tabular}{|c|c|c|c|c|}
\hline Acción & Descripción & Costos 1er año & Costos 2 do año & Costos 3er año \\
\hline Implementación de pantallas LED & compra e instalación de 3 pantallas LED & $S / 25,000.00$ & & \\
\hline Boletin interno & Impresión de 1000 boletines para 12 ediciones & $S / 12,000.00$ & $S / 12,000.00$ & $S / 12,000.00$ \\
\hline Tablón de anuncios & Implementación de tablón de anuncios & $s / 5,000.00$ & & \\
\hline Intranet & Desarrollo de intranet & $S / 40,000.00$ & & \\
\hline \begin{tabular}{|l|} 
Buzón de sugerencias \\
\end{tabular} & Implementación de buzón de sugerencias & $s / 1,500.00$ & & \\
\hline Cafée en la oficina & Catering para reuniones & $s / 3,500.00$ & & \\
\hline \begin{tabular}{|l|} 
Campaña de lanzamiento \\
\end{tabular} & intriga, lanzamiento, mantenimiento & $s / 15,000.00$ & & \\
\hline \begin{tabular}{|l|} 
Evento de lanzamiento \\
\end{tabular} & Empresa productora, catering, grafica, papeleria & $s / 50,000.00$ & & \\
\hline Fiesta de fin de año & & $S / 100,000.00$ & $S / 80,000.00$ & $\mathrm{~S} / 80,000.00$ \\
\hline Kit de onboarding & & $s / 20,000.00$ & & \\
\hline Fiestas patrias & & $s / 5,000.00$ & & \\
\hline \begin{tabular}{|l|} 
Activaciones \\
\end{tabular} & Productora de acticaciones (3 al año) & $S / 30,000.00$ & $S / 30,000.00$ & $S / 30,000.00$ \\
\hline \begin{tabular}{|l|l} 
Evaluaciones \\
\end{tabular} & Encuestas, focus group & $s / 7,000.00$ & $s / 7,000.00$ & $S / 7,000.00$ \\
\hline \multicolumn{5}{|l|}{ Concurso de Innovacion } \\
\hline \begin{tabular}{|l|l} 
Identidad corporativa (manual) \\
\end{tabular} & Agencia de branding & $s / 10,000.00$ & & \\
\hline \begin{tabular}{|l|} 
Branding de oficinas $y$ plantas \\
\end{tabular} & señaletica, letreros, colores corporativos & $S / 100,000.00$ & & \\
\hline \begin{tabular}{|l|} 
Uniformes de colaboradores \\
\end{tabular} & & $\mathrm{S} / 50,000.00$ & & \\
\hline \begin{tabular}{|l|} 
Capacitaciones equipo humano \\
\end{tabular} & & $S / 50,000.00$ & $S / 50,000.00$ & $\mathrm{~S} / 50,000.00$ \\
\hline Equipos de oficina & & $S / 100,000.00$ & & \\
\hline \begin{tabular}{|l|} 
gastos de viaje y representación \\
\end{tabular} & taxis, pasajes, viaje & $S / 100,000.00$ & $S / 100,000.00$ & $S / 100,000.00$ \\
\hline Total & & $S / 724,000$ & S/279,000 & S/279,000 \\
\hline
\end{tabular}

\section{Indicadores de Seguimiento y control}

A continuación, hago mención de algunas métricas (KPI's) para medir la efectividad de la comunicación interna en la organización.

- Encuesta de clima: \% de empleados que valoran positivamente las acciones/canales/herramientas/calidad de la comunicación interna desarrollada por la organización.

- Encuesta de clima: \% de empleados que valoran de manera positiva el tiempo que dedica la empresa a escucharlos.

- Encuesta de recordatorio de la comunicación: frecuencia de canales, percepción del mensaje.

- Encuesta a boca de urna, ¿qué significa Awana para ti? 
- Número de entradas a intranet

- $\%$ de click abierto en correo electrónico

- $\quad \%$ de colaboradores que participan en las actividades 


\section{Diagnóstico y Plan de Comunicación Externa}

\section{Diagnóstico}

La empresa Confecciones SAC hasta la fecha no ha contado con un departamento de comunicaciones.

Ha realizado acciones de comunicación interna (detalladas en el capítulo anterior); sin embargo, al ser una empresa productora y no ha tenido acciones de comunicación externa, más que relaciones comerciales con sus actuales clientes.

Solo se ha contado con una página web muy básica.

Al ser uno de sus objetivos, lanzar una nueva marca, ve necesaria la creación de un departamento de comunicaciones que pueda gestionar sus comunicaciones, tanto interna, como externa.

\section{Plan de comunicación externa}

Hoy en día una empresa está en relación con múltiples elementos, factores y agentes que se mueven en entornos cambiantes y pueden afectar sus decisiones. Muchos de estos agentes son llamados "stakeholders" y son parte del ecosistema de las organizaciones.

Actualmente, la comunicación en un aliado estratégico para las organizaciones. Hoy en día, el poder de las comunicaciones online puede elevar el posicionamiento de una marca o caso contrario hundirla, el poder lo tiene el usuario y nosotros tenemos que posicionarnos y dejar una percepción positiva.

\subsection{Estrategia y Objetivos}

2.2.1 Objetivo General: Lanzamiento y posicionamiento de la nueva marca entre los principales grupos de interés.

\subsubsection{Objetivos específicos:}


i. Asociar la marca a los valores: peruanidad, calidad, compromiso con el medio ambiente, innovación y colaboración.

ii. Elevar el grado de involucramiento de los proveedores y aliados estratégicos con respecto al medio ambiente.

iii. Incursionar la nueva marca en mercados europeos y en Estados Unidos mediante una plataforma e-commerce durante los próximos 3 años.

iv. Posicionar la marca en un público objetivo con gustos exclusivos y con predilección por los productos eco amigables.

v. Dar a conocer las bondades del algodón pima orgánico como uno de los más finos del mundo.

vi. Posicionar la marca en medios de comunicación digital

\subsection{Público objetivo}

Hombres y mujeres amantes de los productos eco-amigables, con gusto particular en los detalles y la moda exclusiva. Apasionados por la cultura peruana.

Estilo de vida:

- Mujeres modernas: interesadas por la moda y las tendencias.

- Hombres sofisticados: triunfadores, innovadores que buscan la diferenciación y el prestigio.

\subsection{Stakeholders}

a. Medios de comunicación

b. Grupos y activistas medio ambientales 

c. Periodistas
d. Proveedores
e. Fashion \& Life Style Influencers
f. Asociaciones, círculos textiles y de moda
g. Marca Perú

\subsection{Mensajes clave}
a. Perú en una prenda
b. Materias primas con la más alta calidad en el mundo
c. Excelente mano de obra especializada en finos detalles y acabados
d. Empresa socialmente responsable
e. Comprometidos con el cuidado del medio ambiente

\subsection{Estructura del Área}

Como se mencionó en el plan de comunicación interna, se propone la creación de una estructura nueva para el departamento de comunicaciones. 


\section{Planeamiento estratégico}

\begin{tabular}{|c|c|c|c|c|c|c|}
\hline Objetivo & Estrategia & Acciones/medios & Tipo & Público & Frecuencia & Responsable \\
\hline $\begin{array}{l}\text { Asociar la marca } \\
\text { a los valores: } \\
\text { peruanidad, } \\
\text { calidad, } \\
\text { compromiso con } \\
\text { el medio } \\
\text { ambiente, } \\
\text { innovación y } \\
\text { colaboración. }\end{array}$ & $\begin{array}{l}\text { Crear } \\
\text { relaciones con } \\
\text { grupos de } \\
\text { interés } \\
\text { relacionados a } \\
\text { cada ítem; así } \\
\text { como medios } \\
\text { de } \\
\text { comunicación }\end{array}$ & $\begin{array}{l}\text { Reuniones, desayunos } \\
\text { informativos, gabinete } \\
\text { de prensa, foros, } \\
\text { alianzas estratégicas. }\end{array}$ & $\begin{array}{l}\text { Todos } \\
\text { (presencial, } \\
\text { digital, } \\
\text { escrito) }\end{array}$ & $\begin{array}{l}\text { Medios de } \\
\text { comunicación, } \\
\text { Asociaciones, } \\
\text { grupos de } \\
\text { interés }\end{array}$ & Permanente & $\begin{array}{l}\text { Director de } \\
\text { comunicación }\end{array}$ \\
\hline $\begin{array}{l}\text { Elevar el grado de } \\
\text { involucramiento } \\
\text { de los } \\
\text { proveedores y } \\
\text { aliados } \\
\text { estratégicos con } \\
\text { respecto al medio } \\
\text { ambiente. }\end{array}$ & $\begin{array}{l}\text { Alinear a los } \\
\text { proveedores a } \\
\text { mantener } \\
\text { estándares de } \\
\text { calidad/ambien } \\
\text { tal en sus } \\
\text { procedimientos }\end{array}$ & $\begin{array}{l}\text { Invitar a los } \\
\text { proveedores a postular } \\
\text { al ISO } 9001 \text { y al ISO } \\
14001\end{array}$ & $\begin{array}{l}\text { Presencial } \\
\text { Escrito }\end{array}$ & Proveedores & En ocasión & $\begin{array}{l}\text { Director de } \\
\text { Comunicación }\end{array}$ \\
\hline $\begin{array}{l}\text { Incursionar la } \\
\text { nueva marca en } \\
\text { mercados } \\
\text { europeos y en } \\
\text { Estados Unidos } \\
\text { mediante una } \\
\text { plataforma e- } \\
\text { commerce } \\
\text { durante los } \\
\text { próximos } 3 \text { años. }\end{array}$ & $\begin{array}{l}\text { En conjunto a } \\
\text { Marca Perú y } \\
\text { Embajadas del } \\
\text { Perú en el } \\
\text { extranjero, } \\
\text { posicionar el } \\
\text { producto y la } \\
\text { moda peruana. }\end{array}$ & $\begin{array}{l}\text { - Campaña digital con } \\
\text { influencers } \\
\text { extranjeros (España, } \\
\text { Francia, Italia, USA) } \\
\text { y lanzamiento página } \\
\text { web. } \\
\text { - Ferias } \\
\text { internacionales de } \\
\text { Moda. }\end{array}$ & Todos & $\begin{array}{l}\text { Medios de } \\
\text { comunicación, } \\
\text { grupos } \\
\text { estratégicos de } \\
\text { marca país y } \\
\text { perú moda, } \\
\text { embajadas. }\end{array}$ & $\begin{array}{l}\text { Lanzamiento } \\
\text { campaña }\end{array}$ & $\begin{array}{l}\text { Director de } \\
\text { comunicación y } \\
\text { comunicaciones } \\
\text { externas }\end{array}$ \\
\hline
\end{tabular}


Posicionar la marca en un público objetivo con gustos exclusivos y con predilección por los productos eco amigables.
Lanzamiento de campañas en diferentes canales (offline $y$ online).
Dossiers de prensa,

Todos aparición en revistas, mantener buenas

relaciones con

influencers locales.

Difusión en prensa

escrita.

Eventos especiales

por lanzamiento.

Lanzamiento del

nuevo local.
P.O

especificado

previamente.

Influencers.

Medios de

prensa
Permanente

Comunicacione

s externas y

Marketing
Dar a conocer las bondades del algodón pima orgánico como uno de los más finos del mundo.

Posicionar la
marca en medios
de comunicación
digital

\section{Promover} información sobre el tema e incentivar el diálogo sobre las principales materias primas del Perú en el rubro textil

Tener presencia en medios digitales

\begin{tabular}{|l|l|l|l|l|}
\hline $\begin{array}{l}\text { Fomentar charlas, } \\
\text { foros, participación en } \\
\text { ferias textiles. }\end{array}$ & $\begin{array}{l}\text { Presencial, } \\
\text { escrito }\end{array}$ & $\begin{array}{l}\text { Todos los } \\
\text { públicos }\end{array}$ & Ocasionalmente & $\begin{array}{l}\text { Comunicacione } \\
\text { s externas }\end{array}$ \\
\hline $\begin{array}{l}\text { Re potenciar la página } \\
\text { web. } \\
\text { Incursionar la marca } \\
\text { en redes sociales } \\
\text { (Facebook e }\end{array}$ & Digital & Todos & Permanente & \\
Instagram) & & & & $\begin{array}{l}\text { Comunicacione } \\
\text { sexternas y } \\
\text { marketing }\end{array}$ \\
\hline
\end{tabular}

\section{Propuesta de medios y herramientas}




\begin{tabular}{|c|c|c|c|}
\hline Tipo & Público atendido & Acciones/medios & Frecuencia \\
\hline RR.PP & $\begin{array}{l}\text { Clientes, asociaciones, influencers, } \\
\text { medios de comunicación, grupos } \\
\text { de interés }\end{array}$ & $\begin{array}{l}\text { Fiesta de lanzamiento de } \\
\text { Marca }\end{array}$ & Una vez \\
\hline RR.PP & Grupos de interés & $\begin{array}{l}\text { Regalos a principales grupos } \\
\text { de interés }\end{array}$ & Una vez \\
\hline RR.PP & Influencers & Reunión con influencers & Ocasionalmente \\
\hline RR.PP & $\begin{array}{l}\text { Marca Perú, asociaciones } \\
\text { ambientales. }\end{array}$ & $\begin{array}{l}\text { Desayuno-presentación de la } \\
\text { Marca a instituciones públicas } \\
\text { y privadas }\end{array}$ & Una vez \\
\hline RR.PP & $\begin{array}{l}\text { Clientes, asociaciones, influencers, } \\
\text { medios de comunicación, grupos } \\
\text { de interés }\end{array}$ & Inauguración de nuevo local & Una vez \\
\hline RR.PP & $\begin{array}{l}\text { Asociaciones comerciantes, } \\
\text { productores, activistsas, } \\
\text { profesionales del medio. }\end{array}$ & Ferias del Sector Textil & Ocasionalmenrte \\
\hline $\begin{array}{l}\text { RSE + } \\
\text { Imagen }\end{array}$ & $\begin{array}{l}\text { Jóvenes de bajos recursos que } \\
\text { quieran ser diseñadores de moda } \\
\text { que no puedan pagarse una carrera } \\
\text { de diseño. }\end{array}$ & $\begin{array}{l}\text { Concurso de Diseñadores } \\
\text { independientes }\end{array}$ & Una vez al año \\
\hline Prensa & Medios de comunicación & Notas de prensa & Ocasionalmente \\
\hline Prensa & Medios de comunicación & $\begin{array}{l}\text { Fotografías de eventos en } \\
\text { prensa }\end{array}$ & Ocasionalmente \\
\hline Prensa & Medios de comunicación & Dossier de prensa & Ocasionalmente \\
\hline Prensa & Medios de comunicación & Entrevista - reportaje & Ocasionalmente \\
\hline Prensa & Medios de comunicación & $\begin{array}{l}\text { Rueda de prensa y } \\
\text { presentación de marca a } \\
\text { medios de comunicación }\end{array}$ & Una vez \\
\hline Digital & $\begin{array}{l}\text { Clientes, potenciales clientes, } \\
\text { asociaciones, medios de } \\
\text { comunicación, influencers }\end{array}$ & Página Web 2.0 & Permanente \\
\hline Digital & $\begin{array}{l}\quad \text { Clientes, potenciales clientes, } \\
\text { asociaciones, medios de } \\
\text { comunicación, influencers }\end{array}$ & Nueva APP & Permanente \\
\hline Digital & $\begin{array}{l}\quad \text { Clientes, potenciales clientes, } \\
\text { asociaciones, medios de } \\
\text { comunicación, influencers }\end{array}$ & $\begin{array}{l}\text { Redes sociales (Facebook, } \\
\text { Instagram) }\end{array}$ & Permanente \\
\hline Digital & Clientes, potenciales clientes, & $\begin{array}{l}\text { Posicionamiento con } \\
\text { influencers }\end{array}$ & Ocasionalmente \\
\hline Imagen & $\begin{array}{l}\text { Clientes nacionales e } \\
\text { internacionales }\end{array}$ & $\begin{array}{l}\text { Nueva Imagen para la marca. } \\
\text { Top Model Peruana: Juana } \\
\text { Burga }\end{array}$ & Permanente \\
\hline Audiovisual & Clientes, potenciales clientes & Spot de lanzamiento & Una vez \\
\hline Audiovisual & $\begin{array}{l}\text { Clientes, potenciales clientes, } \\
\text { asociaciones, medios de } \\
\text { comunicación,. }\end{array}$ & $\begin{array}{l}\text { Documental sobre las } \\
\text { producción del algodón pima } \\
\text { orgánico en el Perú }\end{array}$ & Una vez \\
\hline
\end{tabular}




\subsection{Acciones tácticas}

\section{Relaciones Públicas}

1. Fiesta de Lanzamiento de Marca: este evento, será el primer foco de exposición de la marca ante los medios de comunicación, influencers, periodistas y grupos estratégicos.

Este evento nos permitirá generar networking y conocer a las principales agentes que sacarán a luz nuestra marca; nos permitirá conocer a nuestros clientes y generar tendencia en medios digitales.

2. Regalos: reforzando la estrategia de engagement, es dar a conocer nuestro producto, acercarlo a los principales grupos de interés, ya sean asociaciones públicas y privadas. Es importante posicionarnos en medio de asociaciones medio ambientales, asociaciones de productores textiles, instituciones como Marca Perú, Perú Moda, Lima Fashion Week, influencers, entre otras.

3. Reunión con Influencers: teniendo un desayuno o un almuerzo, invitar a 5 influencers más reconocidas entre fashion, travel y life style influencers de nuestro país (lanzamiento nacional)

4. Desayuno y presentación de la marca a principales instituciones y asociaciones estratégicas: se invitará a los principales grupos de interés (Marca perú, Perú Moda, asociación de productores textiles, asociaciones medio ambientales, proveedores) a la presentación oficial de la marca exclusivamente para ellos. 
5. Inauguración de nuevo local con showroom excusivo: trabajando en conjunto con marketing, se ha dispuesto habilitar un nuevo local de la marca en el Centro Comercial Larcomar, pues es el Centro Comercial con más aforo extranjero y de turistas. Este local tiene que estar alineado con la propuesta comunicacional de la marca. Nuevamente se invitará a medios de comunicaciones, influenciadores, grupos estratégicos afines, clientes, proveedores.

6. Ferias: las ferias son un tipo de comunicación indirecta, porque el objetivo de estas no es hablar de la marca, sino hablar de la importancia de la producción de algodón pima orgánico y otras materias primas textiles del Perú. Nuestro objetivo es dar a conocer el producto y la mano de obra peruana como elemento de orgullo y peruanidad.

7. Presencia en desfiles de moda: Una vez generadas buenas relaciones con Asociaciones de Moda como Perú Moda o Lima Fashion Week, buscamos participar de estos desfiles de moda.

\section{Imagen + RSE}

1. Lanzamiento del concurso de emprendimiento: Integrando estrategias de responsabilidad social e impulsando el producto y diseño peruano, se invita a todos los jóvenes de bajos recursos que quieran ser diseñadores a participar una vez al año en esta convocatoria. El ganador ganará una beca para estudiar Diseño de Modas, y adicionalmente podrá ser parte de un Internship en la empresa, pudiendo diseñar su propia línea para una campaña. 


\section{Imagen}

\section{Embajadora de la marca, top model Juana Burga:}

Juana, actualmente es la única Top Model peruana con presencia en las más altas pasarelas del mundo. Dentro de las estrategias organizacionales, tenemos el objetivo de lanzar la marca en mercados extranjeros, principalmente en países como Francia, Italia, España y Estados Unidos.

La presencia de Juana fortalecerá la marca y además, se busca que dé a conocer y

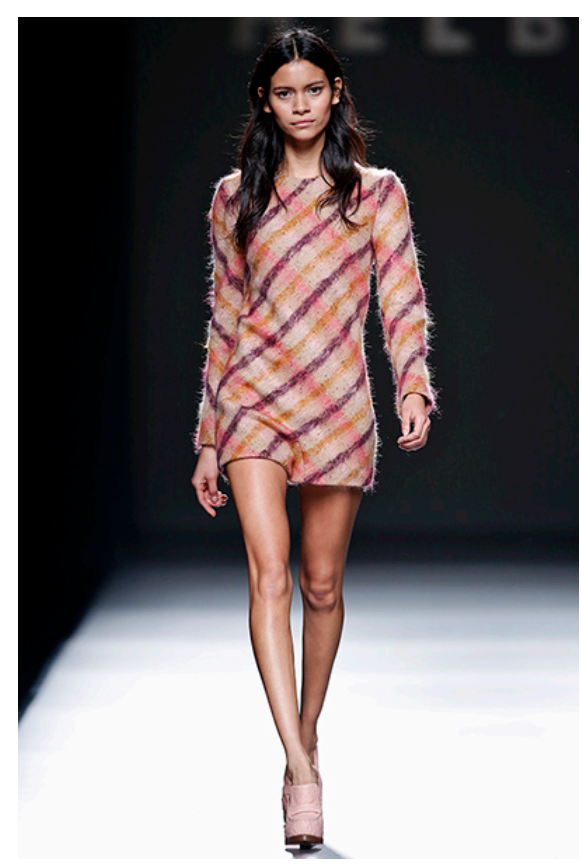
posicionar socialmente la importancia del algodón pima orgánico y el impacto medio ambiental de la industria textil, así como otros ítems sociales, como la mano de obra de calidad detrás de estos procesos. Cabe resaltar que la modelo es activista en temas de medio ambiente y sostenibilidad.

\section{Digital}

1. Página web 2.0: Como estrategia de la marca se busca relanzar la página web, con una interfaz mucho más interactiva y amigable.

Esta página web contará con un Blog donde se hablará de tendencias, y sobretodo de "Moda sostenible", mostrando como la moda impacta en el medio ambiente y como podemos protegerlo. Además, tendrá un landing page donde se 
podrá hacer compras online con delivery express en Estados Unidos, Francia, Italia, España (socios estratégicos: UPS y DHL) con miras a crecer en otros países de Europa y de latinoamérica.

2. APP: se desarrollará una APP para Android e IOS, que incluirá la opción de generar una cuenta, tienda, wishlist y servirá para obtener información y BIG data de nuestros potenciales clientes y clientes actuales. Un estudio de GFK indica que las compras online y por medio de aplicativos han aumentado, y en latinoamerica, un $62 \%$ ya está haciendo compras por internet. Además, en Perú, los clientes pueden usar showrooming, que es una tendencia nueva en donde ves el producto en tienda local y lo compras por internet.

\section{Posicionamiento y relacionamiento con Influencers:}

La estrategia de influencers es muy usada por las marcas hoy en día. Según el estudio Consumers Life, Tendencias Globales de GFK, son 12 los influencers peruanos que tienen renombre nacional e internacional (Latinoamérica). Entre los influencers más sonados y que representan el público objetivo de nuestra marca, hemos pensado en.

- Fashion Blogger Katy Esquivel (2.2millones seguidores) + renombre internacional

- $\quad$ TejiendoPeru (97 mil seguidores)

- Fashion Blogger Natalia Merino (419 mil seguidores)

- Travel blogger Buen Viaje con Maud (84 mil seguidores)

- $\quad$ Travel blogger Luciano Mazzetti de Viaja y Prueba (88 mil seguidores) 
Entre otros personajes se tiene como propuesta:

- Valeria Piazza (300 mil seguidores)

- Natalie Vertiz (1.6 millones de seguidores + presencia TV)

- Juan Diego Florez (57. mil seguidores)

- Maju Mantilla (521 mil seguidores + presencia TV)

- Gianella Neyra (543 mil seguidores + presencia TV)

- Marco Zunino (173 mil seguidores)

- Bruno Pinasco (176 mil seguidores)

- $\quad$ Stephanie Cayo (993 mil seguidores)

\section{Prensa}

1. Notas de prensa: Las notas de prensa son un recurso tradicional, pero siempre serán un recurso válido, sobre todo para posicionar la imagen de nuestra marca en un público que no se mueve en digital. En el lanzamiento, se enviarán notas de prensa a revistas con fines sociales o más especializadas como lo son: Suplemento Ellos y Ellas de Caretas, Diario El Comercio, revista Cosas. Así mismo, una vez realizada la fiesta de lanzamiento se enviará una nota periodística a Cosas, y sección sociales de El Comercio. Más adelante se empleará usar notas de prensa cada vez que la marca tenga un evento fuerte, o una nueva colección.

2. Fotografía de eventos en sección sociales: Aparición en las sesiones de sociales de la revista Cosas, y El Comercio. Eventos: Lanzamiento de Marca, Apertura del nuevo local.

3. Dossier de Prensa: Se enviará este documento a los principales medios de comunicación con la información relevante de la empresa una vez al año. 
4. Entrevista - Reportaje (Gestión): Entrevista de página entera en la revista Gestión al Gerente General de la compañía, donde se hablará del giro estratégico del negocio y del lanzamiento de la nueva línea de negocio.

\section{Rueda de prensa y presentación de marca a medios de comunicación:} para una correcta transmisión a medios de comunicación se prevee realizar una rueda de prensa a cargo del Dircom y portavoz de la marca, y el gerente general, contando con la presencia de la modelo Juana Burga.

\section{Audiovisual}

1. Spot de lanzamiento: El concepto de este spot es la aparición de la modelo en diversos paisajes y entornos del Perú portando la primera colección de prendas. No habrá diálogo, solo serán las imágenes, a medida que pasen los segundos del spot, las imágenes correrán más rápido. El arte del spot es un contraste entre colores, los colores del Perú. No habrá ninguna aparición de personas, más que de la modelo, todos los colores son de elementos como lagos, montañas, arboles, animales, mostrando lo que es Awana. El spot cierra con el claim de la marca: "Perú en una prenda" subtitulado al inglés "Perú in a garment”. La música de fondo será muy suave, producida con violines, piano, y mezcla de zampoña. El spot se difundirá en redes sociales.

2. Documental sobre la producción de algodón pima orgánico en Perú: La realización de este documental tiene por objetivo dar conocer al público nacional e internacional las bondades del algodón pima orgánico peruano y los procesos detrás de su producción, así mismo busca abordar temas de la industria 
textil y como convertirse a la moda sustentable para no tener un impacto ambiental negativo.

\section{Miniserie internacional en capítulos web "Behind your dress": Esta} miniserie de 5 capítulos busca concientizar y dar a conocer a las personas que están detrás de las prendas, como es su día a día y darle importancia al factor humano dentro del proceso de producción de las prendas. Se entrevistará a costureras, tejedoras, diseñadores, entre otros perfiles dentro del sector industrial textil. Esta miniserie se tiene como acción táctica para el lanzamiento internacional de la marca.

4. Spots Storytelling por colección: Hoy en día, las herramientas transmedia y el uso de storytelling se han podido apreciar en campañas internacionales, sin embargo en Perú aún están en pleno auge. El concepto audiovisual de los spots cada vez que la marca lance una nueva colección es mediante mini capítulos de 5 minutos de historias en diversas locaciones del Perú, historias con contenido viral, donde los actores y actrices usan las prendas de la colección.

\subsection{Cronograma (Ver anexo)}

\section{Presupuesto (Ver anexo)}

A continuación, se presenta el presupuesto para el plan de comunicación externa que tiene proyección de 3 años. Cabe mencionar que parte del presupuesto también se ha destinado al plan de comunicación interna.

La empresa presupuestó 15 millones de soles para toda la campaña de lanzamiento por los primeros 3 años, de los cuáles se ha destinado 7 millones el año 1, 4 millones el año 
2 y 4 millones el año 3, esto con la intención de lanzar una campaña agresiva de comunicaciones durante el lanzamiento sin descuidar los años posteriores.

\section{Indicadores de medición e instrumentos de evaluación}

- Estudios de Mercado

- Estudios de reputación

- Encuestas a potenciales clientes

- Tráfico en la página web (google analytics)

- Facebook analytics (fanpage)

- Instagram analytics (Instagram)

- $\quad \%$ de clicks en videos

- $\quad \%$ de shares en videos

- Comentarios en redes sociales. 


\section{Conclusiones}

- La industria textil es un sector complejo, pero con miras a crecer, aun con un apoyo del gobierno limitado. Desde la comunicación se pueden generar muchas acciones para posicionar la materia prima peruana (el algodón pima) y competir con mercados extranjeros y con obra de mano barata.

- Un buen plan de comunicación es estratégico, hay que tener un análisis profundo y exhaustivo del sector para poder entenderlo y generar acciones adecuadas.

- La comunicación no solo aborda posicionar un producto final, uno puede dar a comunicar los procesos, posicionar la materia prima, hay muchas rutas que puede abordar la comunicación externa.

- En medio de tanta acogida a los medios online, no hay que desacreditar a los medios tradicionales $\mathrm{u}$ offline, solo hay que saber direccionarlo para que ambos logren una estrategia agresiva. 


\section{REFERENCIAS}

\section{Libros}

- $\quad$ Aljure, Andres. (2015). El plan estratégico de comunicación. Colombia: Editorial UOC.

- Cervera Fantoni, Angel Luis. (2015). Comunicación Total. Madrid: Esic Editorial.

- Costa, Joan. (2012). El Dircom hoy. Barcelona: CPC Editor.

- Costa, Joan. (2003). Imagen corporativa en el Siglo XXI. Argentina: La Crujía.

\section{Artículos Web}

- Gonzalo Ibañez, Almudena Ramiro, Alejandro Casado. (2018). Evolución y perspectiva del E-commerce para el 2018. 2018, de Kanlli Sitio web: https://www.kanlli.com/wpcontent/uploads/2018/02/evoucion-ecommerce-2018-3.pdf

- GFK. (2017). Evolución del camino de compra, conductas, consideraciones y canales, de GFK Sitio web: https://www.gfk.com/es-pe/insights/press-release/descubre-loshabitos-de-compra-en-futurebuy-2/

- Pilar Riaño. (2016). Moda sostenible: la nueva hoja ruta del sector. 2018, de Dossier Sitio web:

https://www.modaes.es/files/030publicaciones/docs/2016_moda_sostenible.pdf

\section{Diarios online}

- Diario Gestión. (2018). Economía peruana: ¿Cuáles son las expectativas para los próximos 12 meses?. Diario Gestión, p1. Recuperado de https://gestion.pe/economia/economia-peruana-son-expectativas-proximos-12-meses243897

- Diario Gestión. (2018). Produce: Sector prendas de vestir se recuperará en el 2018 y crecería alrededor de 4\%. Diario Gestión, p1. Recuperado de 
https://gestion.pe/economia/produce-sector-prendas-vestir-recuperara-2018-creceriaalrededor-4-224404

- La República. (2018). SNI: sector textil peruano tiene gran oportunidad frente a guerra comercial. Diario la República, p1. Recuperado de https://larepublica.pe/economia/1285292-sni-sector-textil-peruano-mayoresoportunidades-frente-guerra-comercial 


\section{ANEXO 1. Cronograma Comunicación Externa}

\begin{tabular}{|c|c|c|c|c|c|c|c|c|c|c|c|c|c|c|c|c|c|c|c|}
\hline F & & & & & & & & & & & & & & & & & & & \\
\hline 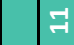 & & & & & & & & & & & & & & & & & & & \\
\hline 9 & & & & & & & & & & & & & & & & & & & \\
\hline ब & & & & & & & & & & & & & & & & & & & \\
\hline$\infty$ & & & & & & & & & & & & & & & & & & & \\
\hline$m$ & & & & & & & & & & & & & & & & & & & \\
\hline$\sqrt[3]{<}<$ & & & & & & & & & & & & & & & & & & & \\
\hline "n & & & & & & & & & & & & & & & & & & & \\
\hline ब & & & & & & & & & & & & & & & & & & & \\
\hline$m$ & & & & & & & & & & & & & & & & & 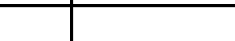 & & \\
\hline$N$ & & & & & & & & & & & & & & & & & 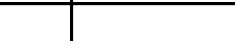 & & \\
\hline$न$ & & & & & & & & & & & & & & & & & & & \\
\hline$\approx$ & & & & & & & & & & & & & & & & & & & \\
\hline न & & & & & & & & & & & & & & & & & & & \\
\hline 윽 & & & & & & & & & & & & & & & & & & & \\
\hline न & & & & & & & & & & & & & & & & & & & \\
\hline$\infty$ & & & & & & & & & & & & & & & & & & & \\
\hline$\approx \curvearrowright$ & & & & & & & & & & & & & & & & & & & \\
\hline$\div \frac{0}{6}$ & & & & & & & & & & & & & & & & & & & \\
\hline 10 & & & & & & & & & & & & & & & & & & & \\
\hline$\sigma$ & & & & & & & & & & & & & & & & & & & \\
\hline m & & & & & & & & & & & & & & & & & & & \\
\hline 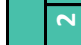 & & & & & & & & & & & & & & & & & & & \\
\hline-1 & & & & & & & & & & & & & & & & & & & \\
\hline$\approx$ & & & & & & & & & & & & & & & & & & & \\
\hline 검 & & & & & & & & & & & & & & & & & & & \\
\hline 웅 & & & & & & & & & & & & & & & & & & & \\
\hline$\sigma$ & & & & & & & & & & & & & & & & & & & \\
\hline$\infty$ & & & & & & & & & & & & & & & & & & & \\
\hline$\because \sqrt{\wedge}$ & & & & & & & & & & & & & & & & & & & \\
\hline $\mid<\frac{1<0}{6}$ & & & & & & & & & & & & & & & & & & & \\
\hline \begin{tabular}{|l|}
10 \\
\end{tabular} & & & & & & & & & & & & & & & & & & & \\
\hline + & & & & & & & & & & & & & & & & & & & \\
\hline$m$ & & & & & & & & & & & & & & & & & & & \\
\hline$N$ & & & & & & & & & & & & & & & & & & & \\
\hline$न$ & & & & & & & & & & & & & & & & & & & \\
\hline 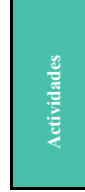 & $\bar{\Xi}$ & 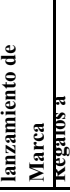 & 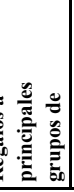 & & $\begin{array}{ll}8 \\
0\end{array}$ & 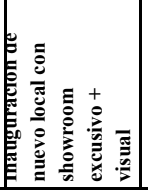 & 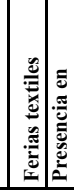 & 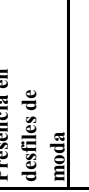 & 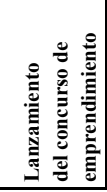 & 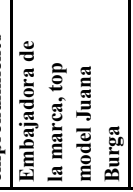 & 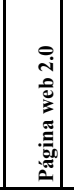 & 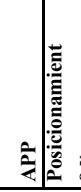 & 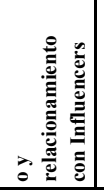 & 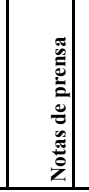 & 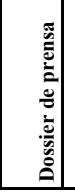 & 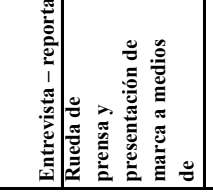 & 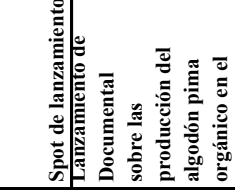 & 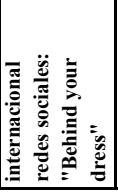 & 然 \\
\hline
\end{tabular}


ANEXO 2. Presupuesto Comunicación Externa

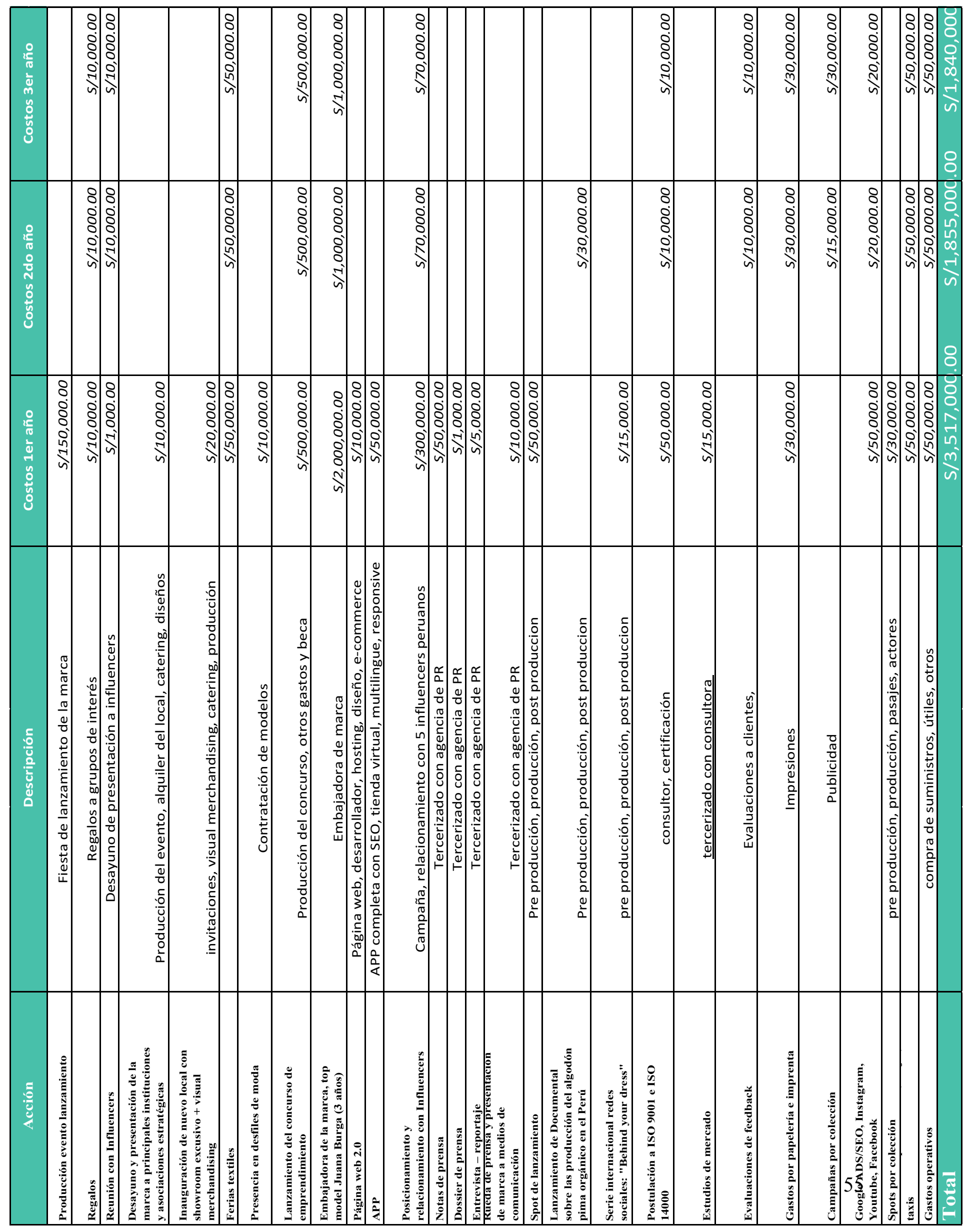

